\title{
RICKETS, CONGENITAL SYPHILIS AND ACHONDROPLASIA IN THE SAME CHILD
}

BY

HUGH T. ASHBY, M.D., F.R.C.P.,

Physician to the Royal Manchester Children's Hospital.

The case here reported is of interest as showing evidence of three different diseases, rickets, congenital syphilis and achondroplasia, making the signs and symptoms difficult to interpret correctly.

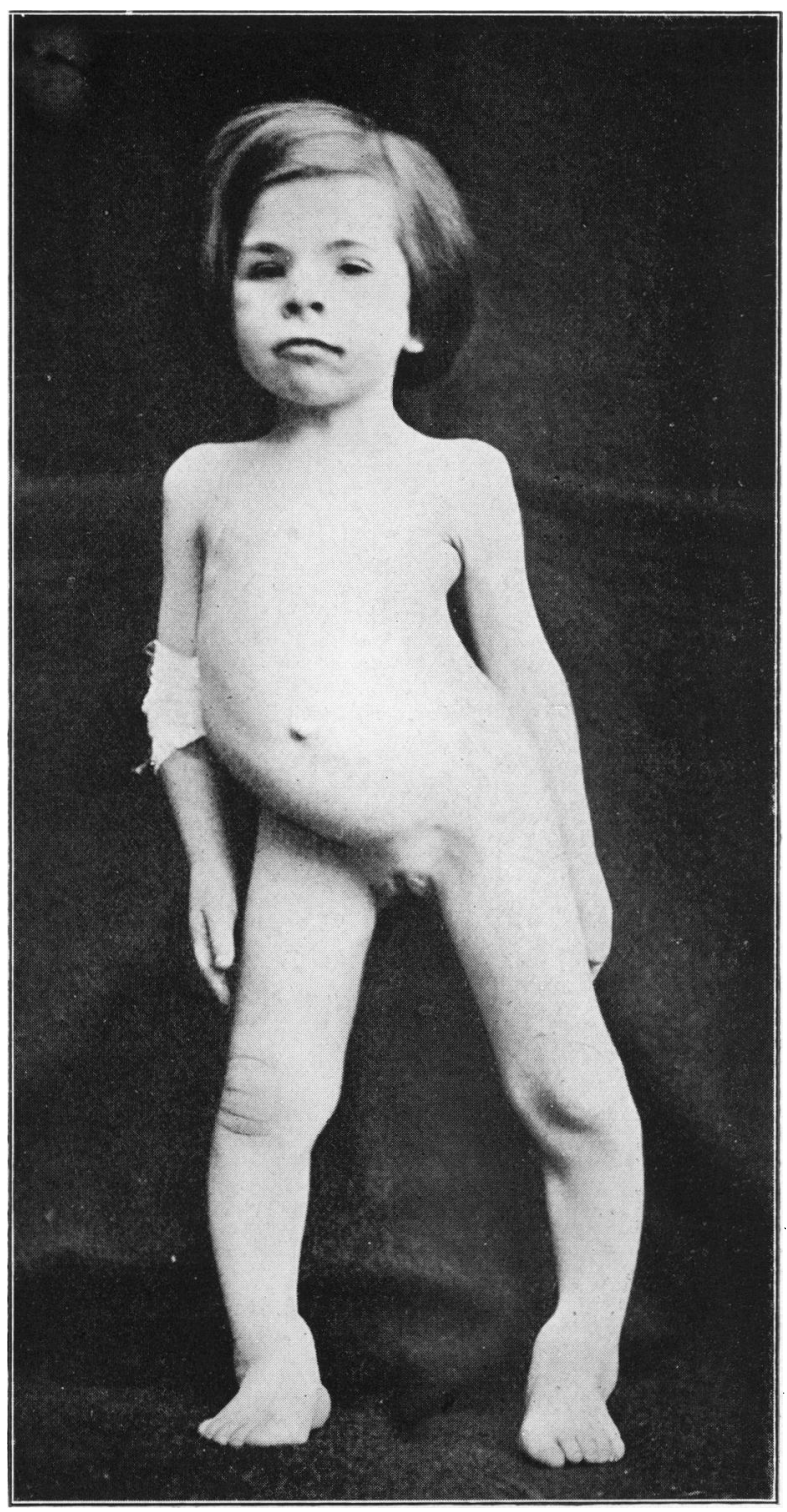

FIG. 1. Girl, age $7 \frac{1}{2}$ years, showing rickets and congenital syphilis. 
The patient is a girl aged $7 \frac{1}{2}$ years, admitted to the Royal Manchester Children's Hospital with a diagnosis of achondroplasia. At first sight this diagnosis is apparently mistaken, as her stature in no way resembles that of achondroplasia. The photograph (Fig. 1) shows that the limbs are in right proportion to the trunk.

She is an only child, though there were two miscarriages previously, and she shows unmistakable signs of congenital syphilis, fissuring of the lips, circumoral eczema, depression of the bridge of the nose, etc. There are,

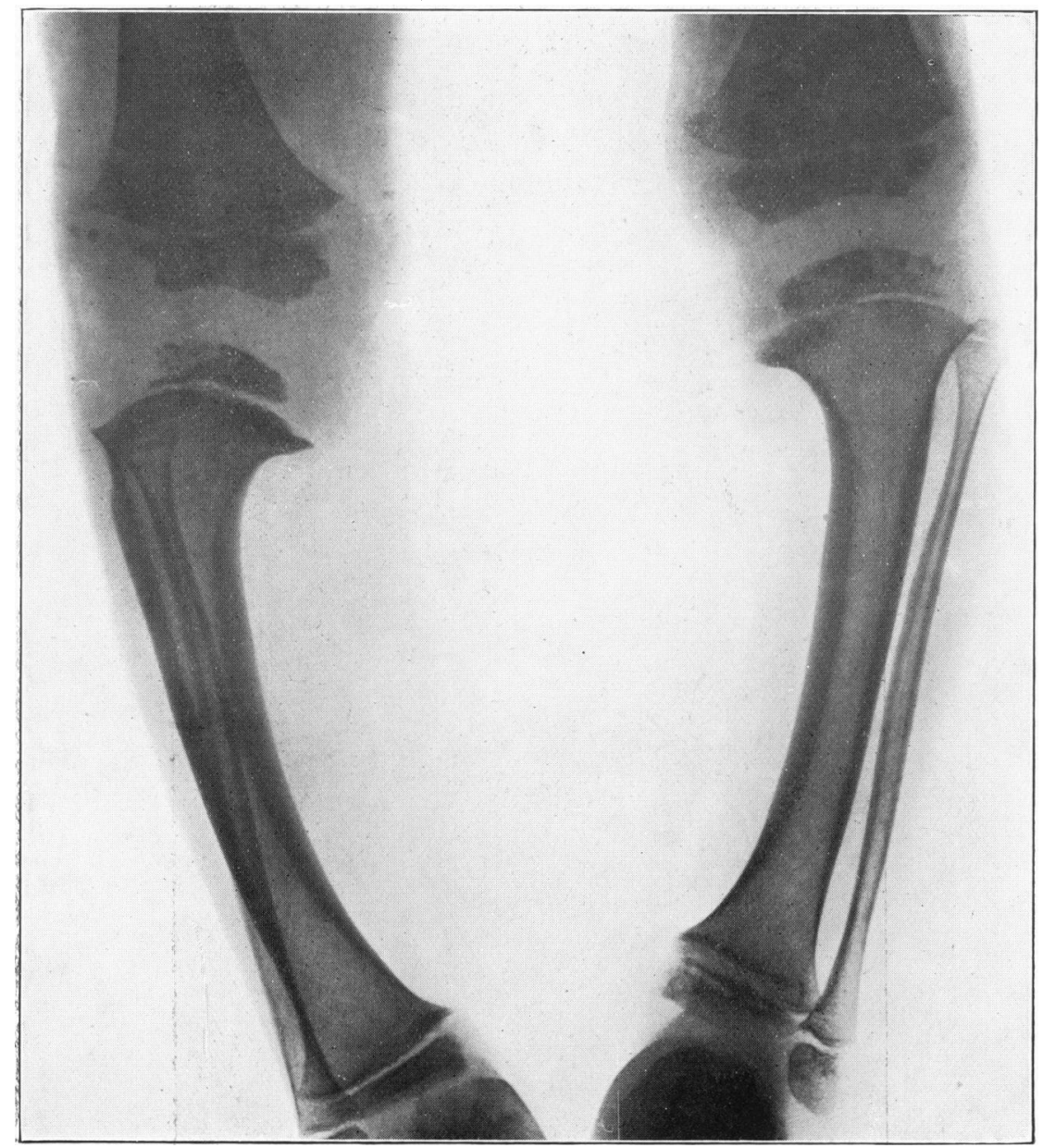

Fı, 2. Tibiæ showing achondroplasia.

however, no specific bone lesions, except perhaps some slight periostitis of the humeri. There are no sabre tibiæ. The Wassermann reaction was strongly positive and remained so in spite of intensive anti-syphilitic treatment. The blood from both parents was also positive. 
The child is also markedly rachitic showing definite epiphysial changes and deformities due to rickets. She is short in stature and there is a congenital scoliosis of the spine.

The radiograms (Fig. 2) are interesting as they show the peculiar condition of the upper ends of the tibiæ. Here there is dense bone with clear cut edges. The bones are lipped and exactly like those of achondroplasia. She is probably an example of a type of achondroplasia not often met with or recognized, as the common type of this disease causes bone changes throughout the body in certain directions. The child also shows no outward signs of achondroplasia, although she was admitted with this diagnosis. The upper ends of the tibiæ are certainly not syphilitic or rachitic.

The difficulty in the interpretation of the radiograms in this case is that the bony changes are not typical of any one disease and are probably the result of more than one cause. 